\title{
INTRAMUSCULAR OXYTOCIN VERSUS SUBLINGUAL MISOPROSTOL AS A COMPONENT OF ACTIVE MANAGEMENT OF THIRD STAGE OF LABOUR FOR PREVENTION OF PRIMARY POST-PARTUM HAEMORRHAGE
}

\author{
Sukumar Mitra1 ${ }^{1}$ Jhumee Baraik ${ }^{2}$
}

${ }^{1}$ Associate Professor, Department of Obstetrics and Gynaecology, Medical College and Hospital, Kolkata, West Bengal, India.

${ }^{2}$ Resident, Department of Obstetrics and Gynaecology, Medical College and Hospital, Kolkata, West Bengal, India.

\section{BACKGROUND}

ABSTRACT

Post-partum haemorrhage is one of the common causes of maternal mortality and morbidity worldwide. Active management of labour is the key element in prevention of post-partum bleeding and complication of third stage of labour. Use of uterotonics is mandatory for prevention of primary post-partum haemorrhage. Many drugs like oxytocin, misoprostol, ergometrine alone or in combination are used as uterotonic drugs.

Our aim is to compare the efficacy and safety of intramuscular oxytocin and sublingual misoprostol as an uterotonic agent used to minimise post-partum bleeding.

\section{MATERIALS AND METHODS}

800 selected antenatal mothers fulfilling the inclusion and exclusion criteria were divided non-randomly into two equal groups of 400 each by using computerised generated randomisation chart. One group received $400 \mathrm{mcg}$ of sublingual misoprostol and the other group received intramuscular oxytocin after the delivery of the baby as a component of active management of third stage of labour for prevention of primary atonic PPH. The efficacy and side effects of the two drugs were assessed.

This study found both sublingual misoprostol and intramuscular oxytocin to be effective in prevention of primary PPH with oxytocin being slightly better than misoprostol, but those with misoprostol had significantly higher incidence of fall of haemoglobin and PCV and significantly higher incidence of fever. Hypotension, though more common with oxytocin, was not found to be significantly higher than in patients treated with misoprostol. On the contrary, mean fall of SBP and DBP was significantly more in the misoprostol group.

This study established that both misoprostol and oxytocin are equally effective in prevention of primary PPH with oxytocin slightly better than misoprostol. Misoprostol can be used as an alternative to oxytocin in low resource areas. Both oxytocin and misoprostol are capable of minimising blood loss in $90 \%$ of the individuals.

\section{RESULTS}

This study found both sublingual misoprostol and intramuscular oxytocin to be effective in prevention of primary PPH with oxytocin being slightly better than misoprostol, but those with misoprostol had significantly higher incidence of fall of haemoglobin and PCV and significantly higher incidence of fever. Hypotension, though more common with oxytocin was not found to be significantly than those treated with misoprostol. On the contrary, mean fall of SBP and DBP was significantly more in the misoprostol group.

\section{CONCLUSION}

This study established that both misoprostol and oxytocin are equally effective in prevention of primary PPH with oxytocin being slightly better than misoprostol. Misoprostol can be used as an alternative to oxytocin in low resource areas. Both oxytocin and misoprostol are capable of minimising blood loss in $90 \%$ of the individuals.

\section{KEY WORDS}

Post-Partum Haemorrhage, Active Management of Third Stage of Labour, Intramuscular Oxytocin, Sublingual Misoprostol.

HOW TO CITE THIS ARTICLE: Mitra S, Baraik J. Intramuscular oxytocin versus sublingual misoprostol as a component of active management of third stage of labour for prevention of primary post-partum haemorrhage. J. Evolution Med. Dent. Sci. 2018;7(28): 3204-3210, DOI: $10.14260 /$ jemds/2018/721

\section{BACKGROUND}

Post-Partum Haemorrhage (PPH) remains one of the leading causes of maternal deaths in both industrialised and non-

'Financial or Other Competing Interest': None.

Submission 15-05-2018, Peer Review 25-06-2018,

Acceptance 01-07-2018, Published 09-07-2018.

Corresponding Author:

Dr. Jhumee Baraik,

Room No. 23,

Bidhumukhi PG Ladies Hostel,

88 College Street, Medical College,

Kolkata-700073, West Bengal, India.

E-mail: docjbaraik@gmail.com

DOI: $10.14260 /$ jemds $/ 2018 / 721$ industrialised nations. Health organisation estimated (WHO) $29.6 \%$ of all maternal deaths worldwide, mostly in the low resource countries with more than half occurring in SubSaharan Africa and one-third occurring in South Asia.1,2 In fact, PPH along with hypertension and sepsis is one of the infamous "triad" of causes of maternal deaths. Approximately, 140,000 women die annually from PPH worldwide and more than $50 \%$ of these mortalities occur within the first 24 hours post-partum.3,4,5 WHO has also estimated that not only is maternal mortality high, but also approximately 20 million mothers per year suffer significant morbidity from $\mathrm{PPH} .3,6$

All women who carry the pregnancy beyond 20 weeks of gestation are at risk for PPH and its sequelae. Primary PPH is considered when there is blood loss from or within genital 
tract exceeding $500 \mathrm{~mL}$ following vaginal delivery or 1000 $\mathrm{mL}$ following caesarean section or which causes deterioration in maternal health in first 24 hrs. post-partum (WHO). Uterine atony accounts for $70 \%$ of primary PPH.7,8,3 Other causes include trauma, retained tissues and coagulopathies.

In developed countries PPH is a largely preventable and manageable condition, but in the developing countries mortality from PPH still remains high. WHO has continuously promoted active management of third stage of labour as an intervention for the prevention of PPH. This intervention is a package comprising of clamping and cutting umbilical cord administration of an uterotonic drug and delivery of the placenta by controlled cord traction followed by uterine massage. Intramuscular or (IM) or Intravascular (IV) oxytocin (10 IU) is recommended as uterotonic of choice. Other injectable uterotonics (Ergometrine/ methylergometrine or combination of oxytocin and ergometrine) and Misoprostol by various route is recommended as an alternative where oxytocin is not available.

Recognising the sequence of events in the third stage of labour and understanding the mechanism of placental separation may aid the detection of cases at risk for thirdstage complications and the management of pathology. Prostaglandins and oxytocin are the biochemical agents primarily involved in the third stage of labour. During the first and second stages of labour, only $\mathrm{PGF}_{2 \alpha}$ and oxytocin are significantly raised in maternal plasma compared with prelabour concentrations. At 5 minutes after birth, maternal PGF2 $\alpha$ concentrations peak at about twice the levels found at the commencement of the second stage. A rapid increase in prostaglandin concentrations is also found in umbilical cord venous blood suggesting that this postpartum prostaglandin surge originates in the placenta. ${ }^{9}$ After placental separation, the concentration decreases but at rates slower than the metabolic clearance of prostaglandin, indicating that its production continues in the decidua and the myometrium. Plasma oxytocin also drops to pre-labour levels within 30 minutes of delivery, unless sustained by exogenous administration. Continuous real-time ultrasound, performed during the third stage of labour, has revealed that the process of placental separation can be divided into four phases.10 1. Latent- uterine wall at the placental site remains thin; placenta free wall contracts; 2 . Contraction- thickening of uterine wall at the placental site; 3 . Detachment- actual separation of the placenta from the adjacent uterine wall; 4. Expulsion- sliding of the placenta out of the uterine cavity. Forceful uterine contractions in the latent phase induce shearing forces between the uterine wall and the unyielding placental tissue, initiating the separation of the placenta. A wave of separation begins at one of the placental poles, usually at a point near to the lower segment and propagates toward the fundus during the contraction and detachment phases. ${ }^{11}$

Separation of the fundal placenta begins at more than one of the placental poles and the central part is last to separate. (This is the reverse of the Schultze and Mathews Duncan mechanisms described in most texts). In almost half of the cases with a previous caesarean section the separation pattern is reversed, commencing at the fundus, suggesting that myometrial strength at the region of the uterine scar may have been compromised.11
Causes of post-partum haemorrhage are uterine atony, trauma, retained placenta and coagulopathy, commonly referred to as the "four T's."12 Tone: Uterine atony, Trauma: Injury to the birth canal, Tissue: Retention of tissue from the placenta or foetus may lead to bleeding, Thrombin: Coagulopathies.

Active management of third stage includes administration of a prophylactic oxytocic agent like oxytocin or prostaglandin within 2 minutes of the baby's birth to induce uterine contraction, cutting and clamping of the cord to enhance placental separation and placental delivery by controlled cord traction. The FIGO-ICM definition includes use of an uterotonic immediately following delivery of the foetus, controlled cord traction and fundal massage immediately after delivery of the placenta followed by palpation of the uterus every 15 minutes for 2 hours to assess the continued need for massage. Cord clamping is excluded based on research indicating that delayed clamping benefits preterm (and probably term) infants. ${ }^{13}$

There no longer appears to be any valid argument in favour of the physiologic approach, because two substantive studies comparing active management with expectant management have clearly indicated the advantages of active management. Oxytocin (Pitocin) or oxytocin combined with ergometrine (Syntometrine), therefore remain the preferred drugs for routine use in developed countries. Oxytocin is a hormone, neuropeptide and medication. As a medication, it is used to cause contraction of the uterus for induction of labour, augmentation of labour and for prevention and treatment of post-partum haemorrhage. Oxytocin was discovered in 1952.14 Half-life is 3 minutes when used as intravenous infusion. Oxytocin is mainly used in induction and augmentation of labour, prevention and treatment of PPH. Misoprostol was developed in 1973.15 Misoprostol is a longer acting synthetic prostaglandin (PGE-1) derivative. It has strong uterotonic action, causes softening of cervix. It is available in $25 \mathrm{mcg}, 100 \mathrm{mcg}, 200 \mathrm{mcg}$ and $600 \mathrm{mcg}$ tablet preparation. It is stable at room temperature and can be administered through oral, buccal, sublingual, vaginal and rectal route. In sublingual route, it acts rapidly with its highest bioavailability. Misoprostol is used for the prevention of NSAID-induced gastric ulcer needed to achieve gastric acid suppression, in labour induction, abortion and prevention and treatment of PPH. Misoprostol use was found to be $38 \%$ reduction in maternal deaths due to post-partum haemorrhage in resource-poor communities. ${ }^{16}$ Misoprostol is recommended due to its cost, effectiveness, stability and low rate of side effects. ${ }^{17}$ Oxytocin must be given by injection, while misoprostol can be given orally or rectally for this use, making it much more useful in areas where nurses and physicians are less available. ${ }^{18}$ This study is an attempt to compare efficacy and safety of IV oxytocin and sublingual misoprostol as an uterotonic to minimise the post-partum bleeding, thus preventing mortality and morbidity from PPH.

\section{Aims and Objectives}

The aim of the study was to evaluate the efficacy of sublingual (SL) misoprostol in prevention of primary post-partum haemorrhage and comparison of its efficacy with IM oxytocin. The secondary objective of the study was to evaluate the safety, side effects and acceptability of SL misoprostol in comparison with IM oxytocin. 


\section{MATERIALS AND METHODS}

Study was conducted in labour ward and adjacent postnatal observation ward, Eden Hospital, Department of Obstetrics and Gynaecology Medical College, Kolkata. Study population were term uncomplicated antenatal mothers in active labour in labour ward. Inclusion criteria were age above 18 years, term pregnancy, anticipated uncomplicated vaginal delivery. Exclusion criteria were multi-foetal pregnancy, prolonged first and second stage of labour, operative vaginal delivery (Forceps or ventouse), preterm labour, known congenital uterine anomaly, confirmed intrauterine foetal death, maternal malaria or other bacterial infection, maternal heart disease, caesarean delivery, antepartum haemorrhage, induced or augmented labour, malpresentation, known maternal coagulation disorder and traumatic PPH. Study design was an open label randomised clinical trial. Randomisation was done by computerised random sequence generator and the study period was June 2016 to May 2017.

The Study was Open Non-Randomised Controlled Trial. 800 Patients were taken for Convenience for the Study and Divided into Two Groups-

\section{Study Design}

Non-randomised controlled trial.

\section{Study Group \\ Group-A: 400 patients. \\ Group-B: 400 patients.}

We recruited 400 patients in each arm. Permission of Institutional Ethical Committee had been taken prior to initiation of the study. After taking informed consent, the mothers who were eligible and agreed for the study underwent haemoglobin $(\mathrm{Hb} \%)$ and packed cell volume (PCV) testing before delivery. General and obstetric examination was done and vitals were recorded. After delivery they were non-randomly assigned to receive either misoprostol $400 \mathrm{mcg}$ sublingually or oxytocin $10 \mathrm{IU}$ intramuscularly within 1 min of birth of baby. Delayed cord clamping was preferred. Placenta and afterbirths were delivered by controlled cord traction and placenta was examined for its completeness. Other cares like bladder emptying, repair of episiotomy and lacerations were done accordingly. Vitals were recorded again 30 minutes after birth and the patients were monitored up to $24 \mathrm{hrs}$. postpartum. Pallor was re-evaluated at the end of $24 \mathrm{hrs}$. Blood loss was measured by draining the plastic sheets on the labour table into calibrated container, by weighing the soaked gauze, cotton etc. and subtracting their dry weight and by weighing the wet pads used in the first $24 \mathrm{hrs}$. and subtracting their dry weight. $\mathrm{Hb} \%$ and PCV was again recorded at $24 \mathrm{hrs}$. after delivery. Parameters studied are $\mathrm{Hb} \%$ and PCV before and 24 hours after delivery, vital signs before and 30 minutes after delivery, estimation of blood loss in $3^{\text {rd }}$ stage of labour and up to 24 hours after delivery using the above-mentioned methods, need of additional uterotonics or additional methods for active management of PPH (if needed), requirement of blood transfusion, recording of duration of $3^{\text {rd }}$ stage of labour.

\section{Data Analysis}

For statistical analysis, data were entered into a Microsoft Excel spreadsheet and then analysed by SPSS 20.0.1. Data have been summarised as mean and standard deviation for numerical variables and count and percentages for categorical variables. The median and the interquartile range have been stated for numerical variables that are not normally distributed. Student's independent sample's t-test was applied to compare normally distributed numerical variables between groups. P-value $\leq 0.05$ was considered for statistical significance.

\section{RESULTS}

\section{Analysis (Table 1)}

800 selected antenatal mothers fulfilling the inclusion and exclusion criteria, divided non-randomly in two equal groups of 400 each by using computerised generated randomisation chart. One group received $400 \mathrm{mcg}$ of sublingual misoprostol and other group received intramuscular oxytocin after the delivery of the baby as a component of active management of third stage of labour for prevention of primary atonic PPH. A comparison in efficacy and side effects of the two drugs were assessed.

Data were entered into a Microsoft Excel spreadsheet and then analysed by SPSS 20.0.1. Data have been summarised as mean and standard deviation for numerical variables and count and percentages for categorical variables. The median and the interquartile range have been stated for numerical variables that are not normally distributed. Student's independent sample's t-test was applied to compare normally distributed numerical variables between groups. P-value $\leq 0.05$ was considered for statistical significance.

Mothers were of age group ranging from 17 to 36 years with both groups having similar composition with maximum in the age group of $21-25$ years $(44.75 \%$ in misoprostol group and $44.5 \%$ in oxytocin group). There was no significant difference $(p=0.069)$ in age group composition. Similarly, both the groups had insignificant composition in relation to parity ( $p$ value=0.846) with $71.75 \%$ nulliparous in misoprostol group and $69.25 \%$ in oxytocin group. Most of the mothers were in healthy BMI range of $20.1-25.0$ (74.75\% in misoprostol group and $71.5 \%$ in oxytocin group). There was no significant difference in BMI composition of the two groups $(\mathrm{p}=0.547)$.

Most of the mothers did not have bradycardia or tachycardia. Only 3\% in misoprostol group and 3.5\% in oxytocin group had pre-existing tachycardia. The difference in composition was significant $(\mathrm{p}=0.038)$. However, tachycardia (pulse $>110 \mathrm{bpm}$ ) was seen in $16.75 \%$ and $22 \%$ in misoprostol and oxytocin group respectively, but the difference in composition of the two groups was not significant $(\mathrm{p}=0.275 \%)$.

Systolic blood pressure (SBP) prior to delivery was noted. All the mothers were normotensive. The difference in composition of the two groups was significant $(p=0.002)$. Oxytocin group had significantly more mothers with low normal SBP (100 - $110 \mathrm{mmHg}$ range). SBP measured in two groups 30 minutes after delivery. Most mothers remained normotensive. The difference in composition of the two groups was not significant ( $\mathrm{p}=0.912)$. Following the trend of SBP most of the mothers had normal Diastolic Blood Pressure (DBP), but the difference in composition of the two groups 
was significant $(\mathrm{p}=<0.001)$ since oxytocin group had more mothers with low normal DBP (60 - $70 \mathrm{mmHg}$ ). DBP measured after 30 minutes of delivery. Most of the mothers still remained normotensive. The difference in composition of the two groups was not significant $(\mathrm{p}=0.124)$. Hypotension, defined as $\mathrm{BP}<90 / 60 \mathrm{mmHg}$ was assessed in both the groups. Number of mothers with hypotension were more in the oxytocin group than that of misoprostol (17 vs. $11,4.25 \%$ vs. $2.75 \%)$, but the difference was not significant $(\mathrm{p}=0.248)$.

Pallor was noted before and after delivery. There were 17 and 15 mothers who had pallor comprised of $4.25 \%$ of misoprostol and $3.25 \%$ in oxytocin group respectively. The difference was not significant $(\mathrm{p}=0.041)$. Two $(0.5 \%)$ in the misoprostol group and three $(0.75 \%)$ in the oxytocin group had jaundice. The difference was not significant ( $\mathrm{p}=0.041)$.

$261(65.25 \%)$ mothers in misoprostol group and 250 $(62.5 \%)$ mothers in oxytocin group required episiotomy during the confinement $(\mathrm{p}=0.418)$. Late cord clamping $(>1$ minutes) was the protocol of the hospital and it was followed. However, early clamping of cord was done only in 14 (3.5\%) in misoprostol group and $11(2.75 \%)$ in oxytocin group and the difference was not significant.

Placenta was mostly delivered within 20 minutes of delivery of baby (93\% in misoprostol group and $95.5 \%$ in oxytocin group). Placenta was retained ( $>30$ minutes) in 9 $(2.25 \%)$ cases in misoprostol group and in 6 cases $(1.5 \%)$ in oxytocin group. The difference was not significant.

Fever, defined as temperature $>100$ degrees Fahrenheit was noted in $43(10.75 \%)$ cases in misoprostol group compared to only $2(0.5 \%)$ cases in oxytocin group. The difference was significant $(\mathrm{p}<0.001)$.

Total blood loss assessed in both the groups, PPH (i.e. blood loss > $500 \mathrm{~mL}$ ) occurred in $7.5 \%$ mothers in misoprostol group amongst $4 \%$ were severe and $5.25 \%$ of mothers in oxytocin group of which $2.25 \%$ were severe. The difference was not significant. There was $>10 \%$ decline in haemoglobin concentration seen in 23 (5.75\%) mothers in the misoprostol group and $8(2 \%)$ mothers in oxytocin group. The difference was significant $(\mathrm{p}=0.001) .10 \%$ decline in packed cell volume (PCV) was noted in 23 (5.75\%) mothers in misoprostol group and $4(1 \%)$ mothers in oxytocin group. The difference was also significant $(\mathrm{p}<0.001)$. However, 35 (8.75\%) mothers in misoprostol group and 22 (5.5\%) mothers in oxytocin group received blood transfusion, but that difference was not significant $(p=0.074)$. Additional uterotonics were given when required. 37 mothers $(9.25 \%)$ in the misoprostol group and 24 mothers $(6 \%)$ in the oxytocin group required additional uterotonics and the difference was not significant $(\mathrm{p}=0.083)$. Additional measure in the form of manual removal of the placenta was required in $3(0.75 \%)$ mothers in the misoprostol group and $1(0.25 \%)$ in the oxytocin group. The difference was not significant.

\begin{tabular}{|c|c|c|c|c|}
\hline & \multicolumn{2}{|c|}{ Group } & \multirow{3}{*}{$\begin{array}{c}P \\
\text { value }\end{array}$} & \multirow{3}{*}{ Significance } \\
\hline & \multirow{2}{*}{\begin{tabular}{|c|}
$\begin{array}{c}\text { Misop- } \\
\text { rostol }\end{array}$ \\
Mean+SD \\
\end{tabular}} & \multirow{2}{*}{\begin{tabular}{|l} 
Oxytocin \\
Mean \pm SD
\end{tabular}} & & \\
\hline & & & & \\
\hline $\mathrm{BMI}\left(\mathrm{kg} / \mathrm{m}^{2}\right)$ & $\begin{array}{c}21.77 \pm \\
2.07\end{array}$ & $\begin{array}{l}21.98 \\
\pm 2.35\end{array}$ & 0.193 & $\begin{array}{c}\text { Not } \\
\text { significant }\end{array}$ \\
\hline $\begin{array}{l}\text { Increase in pulse } \\
\text { rate }\end{array}$ & $\begin{array}{c}7.44 \pm \\
8.49\end{array}$ & $\begin{array}{c}8.06 \\
\pm 8.08\end{array}$ & 0.290 & $\begin{array}{c}\text { Not } \\
\text { significant }\end{array}$ \\
\hline $\begin{array}{c}\text { Decrease in SBP } \\
(\mathrm{mmHg})\end{array}$ & $\begin{array}{c}1.52 \pm \\
5.82\end{array}$ & $\begin{array}{c}1.17 \\
\pm 6.42\end{array}$ & 0.420 & $\begin{array}{c}\text { Not } \\
\text { significant }\end{array}$ \\
\hline
\end{tabular}

\begin{tabular}{|c|c|c|c|c|}
\hline $\begin{array}{c}\text { Decrease in DBP } \\
\text { (mmHg) }\end{array}$ & $\begin{array}{c}1.48 \pm \\
5.26\end{array}$ & $\begin{array}{c}0.27 \\
\pm 6.09\end{array}$ & 0.003 & $\begin{array}{c}\text { Not } \\
\text { significant }\end{array}$ \\
\hline Increase in Temp. & $\begin{array}{c}0.29 \pm \\
0.89\end{array}$ & $\begin{array}{c}-0.04 \\
\pm 0.31\end{array}$ & $<0.001$ & Significant \\
\hline $\begin{array}{c}\text { Delivery to cord } \\
\text { clamping (min) }\end{array}$ & $\begin{array}{c}1.29 \pm \\
0.22\end{array}$ & $1.2 \pm 0.15$ & $<0.001$ & Significant \\
\hline $\begin{array}{c}\text { Delivery to } \\
\text { placental } \\
\text { expulsion (min) }\end{array}$ & $\begin{array}{c}11.41 \pm \\
6.77\end{array}$ & $\begin{array}{c}10.49 \pm 5.7 \\
2\end{array}$ & 0.038 & $\begin{array}{c}\text { Not } \\
\text { significant }\end{array}$ \\
\hline $\begin{array}{c}\text { Total blood loss } \\
\text { (ml) }\end{array}$ & $\begin{array}{c}387 \pm 191.9 \\
1\end{array}$ & $\begin{array}{c}386.03 \\
\pm 149.23\end{array}$ & 0.937 & $\begin{array}{c}\text { Not } \\
\text { significant }\end{array}$ \\
\hline $\begin{array}{c}\text { Decrease in } \\
\text { Hb (g/dL) }\end{array}$ & $\begin{array}{c}0.34 \pm \\
0.41\end{array}$ & $0.27 \pm 0.28$ & 0.002 & $\begin{array}{c}\text { Not } \\
\text { significant }\end{array}$ \\
\hline \multicolumn{7}{|c|}{$1.18 \pm$} \\
Decrease in PCV & $\begin{array}{c}1.1 \\
1.04 \pm 0.9\end{array}$ & 0.040 & $\begin{array}{c}\text { Not } \\
\text { significant }\end{array}$ \\
\hline $\begin{array}{c}\text { Table 1. Table showing Mean of different Parameters in } \\
\text { two groups and their Significance }\end{array}$ \\
\hline \multicolumn{5}{|c}{}
\end{tabular}

\section{DISCUSSION}

Pregnancy and childbirth related complications account for nearly 290,000 deaths of mothers worldwide. ${ }^{1}$ Post-partum haemorrhage $(\mathrm{PPH})$, sepsis and preeclampsia/ eclampsia are the three infamous 'triad' of causes that causes majority of maternal deaths worldwide. PPH claims the top spot as the highest numbers of maternal deaths are attributed to PPH alone; $29.6 \%$ to be precise (WHO). About 140,000 mothers die of PPH every year and $50 \%$ of them die in the first 24 hours after childbirth (i.e. primary PPH). Moreover, the underdeveloped and developing countries like India bear the burden of most of these deaths, chiefly because of lack of awareness and infrastructure. Labour and delivery are very crucial events in a woman's life. Complications like PPH can endanger her life leading to significant morbidity and even mortality. WHO has strongly recommended for active management of third stage of labour (AMTSL) ${ }^{10}$ by administration of uterotonics immediately after delivery of the baby, controlled cord traction (if delivery attended by skilled birth attendants) and monitoring of uterine tone by palpation and for prevention of PPH. There is no role of expectant management. As an uterotonic, oxytocin is the preferred drug. But since oxytocin requires maintenance of cold chain to preserve its efficacy, heat-stable compounds like misoprostol may be a viable alternative to oxytocin in resource poor settings like India. Our current study intends to investigate the comparative efficacy of these two drugs (Oxytocin and misoprostol) for prevention of primary PPH, as a component of AMTSL and also to find out the side effect profiles of these two drugs. The present study was an openlabel randomised clinical trial conducted from June 2016 to May 2017. It included total of 800 antenatal patients meeting the eligibility criteria (i.e. > 18 years, singleton term pregnancies who were anticipated to have uncomplicated vaginal deliveries). Informed consent was obtained from all of them and general and obstetric examinations were performed. Their vitals were recorded before and 30 minutes after delivery. Laboratory parameters, namely Haemoglobin (g/dL) and PCV (\%) were done before and 24 hours after delivery. After delivery they were randomly assigned to receive either oxytocin (10 IU intramuscular) or misoprostol (400 mcg sublingual) within 1 minute of delivery of baby. Placenta and after-births were delivered by controlled cord traction. Other cares like bladder emptying, repair of episiotomy were done accordingly. If bleeding was $>500 \mathrm{~mL}$ 
or placenta was not separated by 30 minutes, active management of PPH was carried out by medical or surgical means as required. All the patients were monitored for 24 hours. Blood loss was calculated by collecting blood drained from the labour tables into calibrated containers, by weighing soaked gauze and cottons and subtracting their dry weight and by weighing the wet sanitary pads used in the first 24 hours and subtracting their dry weight.

Plan of analysis was to first compare the basic characteristics of the two groups (i.e. age, parity, living issue, BMI, pulse rate, SBP, DBP, presence of pallor, presence of jaundice and temperature) to find any confounding factors. This was followed by comparison of total blood loss (within first 24 hours), \% fall of haemoglobin and \% fall of PCV as measures of severity of PPH. Finally, the comparison of side effect profiles was done by calculating the incidence of hypotension ( $\mathrm{BP}<90 / 60 \mathrm{mmHg}$ ) and fever (temp $>100$ degrees F). Additionally, requirement of episiotomy was also compared. Need for additional uterotonics, additional measures (e.g. manual removal of placenta in case of retained placenta > 30 minutes) and need for blood transfusion in both groups were also investigated.

Most of the patients in both groups were in the age group of 21 - 25 years $(44.75 \%$ vs. $44.5 \%$ in misoprostol vs. oxytocin). Most of them were primiparas $(71.75 \%$ vs. $69.25 \%)$. Number of patients with para 2 were $19(4.75 \%)$ in misoprostol group and $18(4.5 \%)$ in oxytocin group. These differences in age $(\mathrm{p}=0.669)$, parity $(\mathrm{p}=0.846)$ and living issue. $(\mathrm{P}=0.714)$ were not statistically significant. Regarding BMI most patients belonged to the normal BMI range of 20.1$25.0 \mathrm{~kg} / \mathrm{m}^{2}(74.75 \%$ vs. $71.5 \%)$. Number of overweight patients in both groups were $4(1 \%)$ in misoprostol group and $8(2 \%)$ in oxytocin group. The differences in BMI composition of two groups were not statistically significant $(\mathrm{p}=0.547)$. The difference of mean BMI of two groups was also not significant statistically $(21.77 \pm 2.07$ vs. $21.98 \pm 2.35$; $\mathrm{p}=0.193$ ). Comparison of vital signs before delivery showed most patients did not have tachycardia (pulse rate 71 . $80 / \mathrm{min}-41.25 \%$ vs. $34.25 \%$, $81-90 / \mathrm{min}-30 \%$ vs. $27 \%$ ). Most of them were normotensive (SBP 111 - $120 \mathrm{mmHg}$ $50.25 \%$ vs. $39.25 \%, 101-110 \mathrm{mmHg}-24.25 \%$ vs. $35 \%$; and DBP 71 - 80 mmHg- 55\% vs. 57.75\%, 60 - 70 mmHg- 20.25\% vs. $30.75 \%$ ). These differences were significant as the oxytocin group had significantly more number of patients in the lower normal range $(\mathrm{p}=0.002$ for SBP and $\mathrm{p}<0.001$ for $\mathrm{DBP})$, but they were not hypotensive ( $\mathrm{BP}<90 /<60 \mathrm{mmHg}$ ), or hypertensive (BP >140/>90 $\mathrm{mmHg}$ ) patients to begin with. Pallor was present in 17 (4.25\%) and 15 (3.75\%) patients in each group respectively, but the difference was not significant $(\mathrm{p}=0.718)$. Similarly, icterus was present in $2(0.5 \%)$ patients in misoprostol group and $3(0.75 \%)$ in the oxytocin group. This difference was also not significant $(\mathrm{p}=0.654)$. None of the patients in the two groups were febrile (temp $>100$ degrees F) before delivery. Most patients had delayed cord clamping (i.e. > 1 minute after birth) (96.5\% vs. 97.25\%). The difference was not significant $(\mathrm{p}=0.542)$. Mean interval from delivery to cord clamping was $1.29 \pm 0.22$ minutes in misoprostol group vs. $1.2 \pm 0.15$ minutes in the oxytocin group. The difference was significant $(p<0.001)$. Average delivery to placenta expulsion time was 5 - 20 minutes in both groups ( $93 \%$ vs. $95.5 \%$ ). Incidence of retained placenta (delivery to placenta expulsion $>30$ minutes) was $9(2.25 \%)$ cases in misoprostol group and $6(1.5 \%)$ in oxytocin group. The difference was not significant $(\mathrm{p}=0.182)$. The comparison of the mean interval of delivery to placenta expulsion found insignificant difference in the two groups $(11.41 \pm 6.77 \mathrm{~min}$ vs. $10.49 \pm 5.72 \mathrm{~min} ; \mathrm{p}=0.038)$. Additional uterotonics were required in $37(9.25 \%)$ patients in the misoprostol group. The number was $24(6 \%)$ in the oxytocin group. The difference was not significant $(\mathrm{p}=0.083)$. Additional measures in the form of manual removal of placenta were required in 3 $(0.75 \%)$ patients of the misoprostol and $1(0.25 \%)$ patient of the oxytocin group. This difference was also not significant $(p=0.316)$. Assessment of vitals after delivery showed the following: Tachycardia was observed in 67 (16.75\%) patients in the misoprostol group compared to $88(22 \%)$ in the oxytocin group 30 minutes after delivery where the predelivery numbers were $12(3 \%)$ and $14(3.5 \%)$ respectively. Average increase in pulse rate was $7.44 \pm 8.49$ vs. $8.06 \pm 8.08$ in two groups. Difference was not significant $(\mathrm{p}=0.290)$. Although, most patients remained normotensive 30 minutes after delivery in both groups, hypotension (defined by $\mathrm{BP}<90 /<60 \mathrm{mmHg}$ ) was observed in $11(2.75 \%)$ patients in the misoprostol and $17(4.25 \%)$ patients in the oxytocin group. The difference was not significant $(p=0.248)$. No patients developed hypertension in either groups. Average drops in SBP and DBP were $1.52 \pm 5.82 \mathrm{mmHg}$ vs. $1.17 \pm 6.42$ $\mathrm{mmHg}$ for SBP ( $\mathrm{p}=0.420$, not significant) and $1.48 \pm 5.26$ mmHg vs. $0.27 \pm 6.09 \mathrm{mmHg}$ for DBP ( $\mathrm{p}=0.003$, significant). Fever (temp > 100 degrees F) was observed in $43(10.75 \%)$ patients with misoprostol compared to only $2(0.5 \%)$ with oxytocin. This difference was statistically significant $(p<0.001)$. Thus, fever is very common side effect of misoprostol. Average increase in temperature in both groups are $0.29 \pm 0.89$ degree Fahrenheit for misoprostol and minus $0.04 \pm 0.31$ degree $\mathrm{F}$ for oxytocin. This mean difference was also statistically significant $(\mathrm{p}<0.001)$. Comparison of blood loss in both groups showed the incidence of PPH (total blood loss in $24 \mathrm{hrs}$. > $500 \mathrm{~mL}$ ) in both groups as $30(7.5 \%)$ in misoprostol group and 21 (5.25\%) in oxytocin group. Severe PPH ( $>1000 \mathrm{~mL}$ blood loss) was seen in $16(4 \%)$ patients with misoprostol compared to $9(2.25 \%)$ with oxytocin. The differences were not significant $(\mathrm{p}=0.329)$. Vast majority of patients had blood loss below $500 \mathrm{~mL}$ (92.5\% vs. $94.75 \%)$ Thus, both drugs appeared to be effective in preventing PPH in more than $90 \%$ patients. Comparison of average blood loss in both groups showed $387 \pm 191.91 \mathrm{~mL}$ (misoprostol group) vs. $386.03 \pm 149.23 \mathrm{~mL}$ (oxytocin group). The difference was not significant $(p=0.937)$. More than $10 \%$ decline of haemoglobin concentration $24 \mathrm{hrs}$. after delivery was seen in $23(5.75 \%)$ in misoprostol and $8(2 \%)$ in oxytocin group. The difference was significant ( $\mathrm{p}=0.001)$. Mean fall of $\mathrm{Hb} \%$ was $0.34 \pm 0.41 \mathrm{~g} / \mathrm{dL}$ vs. $0.27 \pm 0.28 \mathrm{~g} / \mathrm{dL}$ in two groups and it was significant too $(\mathrm{p}=0.002)$. Fall of PCV followed a similar trend. More than $10 \%$ decline of PCV was seen in 23 (5.75\%) with misoprostol compared to $4(1 \%)$ with oxytocin. The difference again was significant $(\mathrm{p}<0.001)$. Mean PCV decline was $1.18 \pm 1.1 \%$ vs. $1.04 \pm 0.9 \%$. This was also insignificant $(\mathrm{p}=0.040)$. Blood transfusion was needed in $35(8.75 \%)$ patients in misoprostol group compared to $22(5.5 \%)$ in the oxytocin group. But the difference was not significant $(\mathrm{p}=0.074)$.

When existing literature in the concerned topic were sought for, in accordance with our current study most studies 
found that both oxytocin and misoprostol are capable of minimising blood loss following delivery in more than $90 \%$ of individuals. $3,4,5,6$ Study by Saurf, Mauze and Shouayab ${ }^{3}$ (misoprostol $200 \mathrm{mcg}$ SL vs. oxytocin 5 IU IM) showed effectiveness of both drugs in prevention of primary PPH, but oxytocin was marginally more efficacious. Similar results were reported by various authors using various dosage and different routes of administration. Examples include studies by Chaudhuri, Biswas and Mandtil in India ${ }^{4}$ by Atukel, Siedner, Osua and Agaba in Uganda 5 (misoprostol 600 mcg vs. oxytocin 10 IU) by Beverly, Winikoff, Durochar, Darwish and Nguyen in Ecuador, Egypt and Vietnam ${ }^{6}$ (misoprostol 800 mcg vs oxytocin 40 IU in IV infusion) and by Rajaei, Karimi and Shahboodaghi11 (misoprostol 400 mcg vs. oxytocin 20 IU). Examples of studies that found misoprostol more efficacious than oxytocin includes studies by Bellad, Tara, Ganachari and Mallapur in India ${ }^{9}$ and by Gui, Zeteroglu, Karayel et al ${ }^{12}$ (misoprostol $600 \mathrm{mcg}$ vs. oxytocin $20 \mathrm{IU}$ ). Some studies investigated the efficacy of misoprostol alone for prevention of PPH and found it to be quite effective. Examples being studies by Derman, Kodkany, Gardar, Geller and Naik ${ }^{10}$ and by Matagrano and Gabay. ${ }^{13}$ These findings were quite corroborative with our present study, as we also found both drugs to be effective in prevention of PPH in more than $92 \%$ of patients proving their efficacy for the same. Incidence of PPH has been stated in most studies to be $3-6 \%$ with misoprostol ${ }^{4,9}$ and 5.5 - $9 \%$ with oxytocin, ${ }^{4,9}$ which is also corresponding with our current study in which the incidences are 7.5\% with misoprostol and 5.25\% with oxytocin. Most studies have mentioned pyrexia to be a very common side effect of misoprostol ( $44 \%$ vs. $6 \%$ ), ${ }^{6}$ which is also a finding of our present study as well $(10.75 \%$ vs. $0.5 \%$, misoprostol vs. oxytocin) and the difference was significant. Fall of blood pressure has been noticed to be a more frequent finding with oxytocin, ${ }^{3}$ which is also confirmed in our study ( $4.25 \%$ vs. $2.75 \%$, oxytocin vs. misoprostol), although the difference was not significant. In a nutshell, our study found both sublingual misoprostol and intramuscular oxytocin are effective in prevention of primary PPH with oxytocin slightly better than misoprostol, but those with misoprostol had significantly higher incidence of fall of haemoglobin and PCV and significantly higher incidence of fever. Hypotension though more common with oxytocin was not found to be significantly higher number of patients than those with misoprostol. On the contrary, mean fall of SBP and DBP was significantly more in the misoprostol group.

\section{Summary}

The present study was an open label randomised clinical trial conducted with total of 800 antenatal mothers meeting the eligibility criteria. Vitals of the patients were recorded before and 30 minutes after the delivery. After delivery the patients were randomly assigned to receive either Oxytocin (10 IU IM) or Misoprostol ( $400 \mathrm{mcg}$ sublingual) within 1 minute of delivery. Analysis of the data revealed that both groups were comparable with respect to the basic demographic parameters. While comparing basic characteristics of the two groups like age, living issue, BMI, SBP, DBP, presence of pallor, jaundice and temperature was taken into consideration. There was no significant difference in age, parity, living issue and BMI between the two groups. Pallor and icterus were equally prevalent in either groups. After delivery, difference of average increase in pulse rate (before and after delivery), hypotension, average drop of SBP was not statistically significant between two groups, but average drop of DBP before and after delivery was statistically significant and average drop of DBP was more in misoprostol group. Incidence of fever after delivery was more in case of misoprostol group in comparison to oxytocin group and the difference was statistically significant. Regarding blood loss, there was no statistically significant difference of incidence of PPH, severe PPH ( $>1000 \mathrm{~mL}$ blood loss), average blood loss between two groups. Incidence of more than $10 \%$ decline in $\mathrm{Hb} \%$ within $24 \mathrm{hrs}$. after delivery, more than $10 \%$ decline in $\mathrm{PCV}$ and mean fall in $\mathrm{Hb} \%$ were more in case of misoprostol group and it was statistically significant, but there was no statistically significant difference in need for blood transfusion between two groups.

\section{CONCLUSION}

Our study established that both misoprostol and oxytocin are equally effective in prevention of primary atonic PPH with oxytocin being slightly better than misoprostol. However, Misoprostol can be used as an alternative to oxytocin in low resource areas. Both oxytocin and misoprostol are capable of minimising blood loss in more than $90 \%$ of the individuals.

\section{REFERENCES}

[1] WHO. Maternal mortality, fact sheet no. 348. 2010 http/www.who.int/mediacentre/factsheets?fs348/en /index, html

[2] Rushwan H. Misoprostol: an essential medicine for managing postpartum haemorrhage in low resource settings? Int J Gynecol Obstet 2011;114(3):209-10.

[3] Chang J, Elam-Evans LD, Berg CJ, et al. Pregnancy related mortality surveillance--United States 19911997. MMWR Surveil Sum 2003;2:1-2.

[4] Berg CJ, Chang J, Callagham WM, et al. Pregnancy related mortality in United States, 1991-1997. Obstet Gynecol 2003;101(2):289-96.

[5] AbouZahr C. Global burden of maternal death and disability. Br Med Bull 2003;67:1-11.

[6] World Health Organization: WHO recommendations for prevention of post partum haemorrhage, http://www.who.int/healthinfo/ statistics/maternal haemorrhage, pdf.

[7] Cunningham FG, Hauth JC, Leveno KJ. Williams obstetrics. Chapter - 35. 23rd edn. New York: Medical Publishing Division, McGraw-Hill 2010: p. 757-60.

[8] Nirmala K, Zainuddin AA, Ghani NA, et al. Carbetocin versus syntometrine in prevention of post-partum haemorrhage following vaginal delivey. J Obstet Gynaecol Res 2009;35(1):48-54.

[9] Husslein P, Fuchs AR, Fuchs F. Oxytocin - and prostaglandin plasma concentrations before and after spontaneous labour: evidence of involvement of prostaglandins in the mechanism of placental separation. Wien Klin Wochenschr 1983;95(11):36771.

[10] Herman A, Weinraub Z, Bukovsky I, et al. Dynamic ultrasonograghic imaging of the third stage of labor: new perspectives into third-stage mechanisms. Am J Obstet Gynecol 1993;168(5):1496-9. 
[11] Combs CA, Laros RK Jr. Prolonged third stage of labour: morbidity and risk factors. Obstet Gynecol 1991;77(6):863-7.

[12] Anderson JM, Etches D. Prevention and management of postpartum haemorrhage. American family Physician 2007;75(6):875-82.

[13] Van Rheenen PF, Brabin BJ. A practical approach to timing cord clamping in resource poor settings. BMJ 2006;333(7575):954-8.

[14] Corey EJ, Czako, Barbara. Oxytocin. Molecules and medicine. $1^{\text {st }}$ edn. John Wiley \& Sons 2012.

[15] Paul, Maureen. Misoprostol. Management of unintended and abnormal pregnancy: comprehensive abortion care. John Wiley \& Sons 2011.
[16] Derman RJ, Kodkany BS, Goudar SS, et al. Oral misoprostol in preventing postpartum haemorrhage in resource - poor communities: a randomised controlled trials. The Lancet 2006;368(9543):1248-53.

[17] Harshad S, Mohammad Z, Chanpong, et al. Prevention of postpartum haemorrhage in home birth: a Program Implemented Guide (PDF). United States agency for International Development. 2009.

[18] Prata N, Passano P, Bell S, et al. New hope: community-based misoprostol use to prevent postpartum haemorrhage. Health Policy and Planning 2012;368:339-46. 